Review

\title{
A Review on the Effects of Bisphenol A and Its Derivatives on Skeletal Health
}

\author{
Kok-Yong Chin ${ }^{1}$, Kok-Lun Pang², Wun Fui Mark-Lee ${ }^{3}$ \\ 1. Department of Pharmacology, Faculty of Medicine, Universiti Kebangsaan Malaysia \\ 2. Biomedical Science Programme, School of Diagnostic and Applied Health Sciences, Faculty of Health Sciences, Universiti Kebangsaan Malaysia \\ 3. School of Chemical Sciences and Food Technology, Faculty of Science and Technology, Universiti Kebangsaan Malaysia \\ $\square$ Corresponding author: Kok-Yong Chin, Level 17, Preclinical Building, Department of Pharmacology, Universiti Kebangsaan Malaysia Medical Centre, Jalan \\ Yaacob Latif, Bandar Tun Razak, 56000 Cheras, Kuala Lumpur, Malaysia. Email: chinkokyong@ppukm.ukm.edu.my; Tel: +603-9145-9573 \\ (c) Ivyspring International Publisher. This is an open access article distributed under the terms of the Creative Commons Attribution (CC BY-NC) license \\ (https://creativecommons.org/licenses/by-nc/4.0/). See http://ivyspring.com/terms for full terms and conditions.
}

Received: 2018.02.20; Accepted: 2018.06.06; Published: 2018.06.22

\begin{abstract}
Bisphenol A (BPA) is an endocrine disruptor which can bind to the oestrogen receptor. It also possesses oestrogenic, antiandrogenic, inflammatory and oxidative properties. Since bone responds to changes in sex hormones, inflammatory and oxidative status, BPA exposure could influence bone health in humans. This review aimed to summarize the current evidence on the relationship between BPA and bone health derived from cellular, animal and human studies. Exposure to BPA (0.5-12.5 $\mu \mathrm{M})$ decreased the proliferation of osteoblast and osteoclast precursor cells and induce their apoptosis. Bisphenol AF (10 nM) enhanced transforming growth factor beta signalling but bisphenol S (10 nM) inhibited Wnt signalling involved in osteoblast differentiation in vitro. In animals, BPA and its derivatives demonstrated distinct effects in different models. In prenatal/postnatal exposure, BPA increased femoral bone mineral content in male rats (at $25 \mathrm{ug} / \mathrm{kg} /$ day) but decreased femoral mechanical strength in female mice (at $10 \mu \mathrm{g} / \mathrm{kg} / \mathrm{day})$. In oestrogen deficiency models, BPA improved bone mineral density and microstructures in aromatase knockout mice (at very high dose, $0.1 \%$ or $1.0 \% \mathrm{w} / \mathrm{w}$ diet) but decreased trabecular density in ovariectomized rats (at 37 or 370 ug $/ \mathrm{kg} /$ day). In contrast, bisphenol A diglycidyl ether $(30 \mathrm{mg} / \mathrm{kg} /$ day i.p.) improved bone health in normal male and female rodents and decreased trabecular separation in ovariectomized rodents. Two cross-sectional studies have been performed to examine the relationship between BPA level and bone mineral density in humans but they yielded negligible association. As a conclusion, BPA and its derivatives could influence bone health and a possible gender effect was observed in animal studies. However, its effects in humans await verification from more comprehensive longitudinal studies in the future.
\end{abstract}

Key words: Bone; Endocrine discruptor; Oestrogen; Osteoporosis; Xenoestrogen

\section{Introduction}

Bisphenol A (BPA) is a raw material in the production of epoxy resins and polycarbonate plastics used in various household appliances, such as electronic devices/media, children toys, kitchen utensils, water pipes, reusable bottles and food storage containers $[1,2]$. Humans are exposed to BPA directly through oral and topical routes, and indirectly via environmental pollution and food chain [3-6].

The biological effects of BPA are exerted via its bindings to various receptors in the body, including the bone. Due to its structural similarity with the endogenous $17 \beta$-oestradiol (E2), it can exert oestrogenic activities via binding with both oestrogen receptor (ER) a and $\beta$ [7]. However, its affinity is approximately 2000 to 10000 -fold weaker compared to E2 $[7,8]$. Exposure to BPA has been associated with reduced testosterone level, suggesting the possibly antiandrogenic activity of BPA [9]. Furthermore, BPA also possesses the antiandrogenic activity indirectly via upregulation of aromatase enzyme to convert androgens to oestrogens $[10,11]$. The complex 
interactions between BPA and sex hormones could bear significant biological implications to the bone, a target organ of sex hormones.

Besides, BPA also possesses inflammatory activities by stimulating production of pro-inflammatory cytokines, such as tumor necrosis factor- $\alpha$ (TNF- $\alpha$ ) and interleukin (IL)-6, but inhibiting the production of anti-inflammatory cytokines, such as IL-10 and transforming growth factor- $\beta$ (TGF- $\beta$ ), in cellular studies via ER/nuclear factor- $\mathrm{kB}$ (NF- $\mathrm{kB}$ ) signaling pathway [12]. On the other hand, BPA has been shown to produce reactive oxygen species (ROS) via mitochondrial dysfunction, downregulation of antioxidant enzymes, and alteration of cellular signalling [13, 14]. Bisphenol A-mediated ROS production subsequently causes oxidative DNA damage and cell death $[8,15]$. Cross-sectional studies also revealed that BPA exposure was linked with inflammation and oxidative stress in men and postmenopausal women [16, 17]. Since both inflammation and oxidative stress are associated with decreased bone health $[18,19]$, exposure to BPA might have degenerative effects on the bone.

Since BPA influences several biological processes associated with skeletal health, it may have an impact on skeletal development and pathogenesis of osteoporosis. A number of studies have been performed to investigate the skeletal action of BPA and its derivatives but the results are inconsistent [20, 21]. The current review aimed to summarize the evidence on the effects of BPA exposure on bone. Evidence derived from cellular, animal and human studies were considered to provide a comprehensive overview of the subject matter.

\section{Evidence from in vitro studies}

Bone remodelling is a dynamic process orchestrated by three main skeletal cells, i.e. osteoclasts from haematopoietic lineage responsible for bone resorption, osteoblasts from mesenchymal lineage responsible for bone formation, and osteocytes formed from terminally differentiated osteoblasts permanently entombed in the bone matrix. Osteocytes are mediators of the bone remodelling process [22]. The modelling and remodelling of bone can be influenced by endogenous and exogenous factors, including chemical pollutants like BPA, through various receptors present on the cell membrane [23]. When bone remodelling is skewed to bone resorption, bone loss occurs ultimately resulting in osteoporosis. In this section, the effects of BPA on two major cell types, osteoblasts and osteoclasts, are presented. Currently, the evidence on osteocytes is largely absent.
Osteoblasts synthesize the bone matrix and mineralize it. The formation of mature functional osteoblasts involves the expression of transcriptional factors, such as runt-related factor-2 (RUNX2) and osterix by osteoprogenitor cells [24]. Their bone formation activities can be estimated by the secretion of bone matrix protein (type 1 collagen, alkaline phosphatase, osteocalcin, osteopontin etc.) and calcium nodules formed in culture plate [25]. Treatment of BPA $(2.5-12.5 \mu \mathrm{M})$ reduced the osteoblast and bone formation by MC3T3-E1 preosteoblasts, indicated by alkaline phosphatase activities and formation of calcium nodules in the culture plate [26]. Coincidentally, gene expressions of RUNX2, osterix and beta-catenin critical in osteoblast formation were decreased [26]. Apoptosis of MC3T3-E1 associated with increased BCL-2 gene expression (proapoptotic gene) and caspase 9 (initiator of apoptosis) was also found [26]. Comparison of the effects of BPA, p-n-nonylphenol (NP) and bis(2-ethylohexyl)phthalate (DEHP) on M3T3-E1 preosteoblasts were performed by Kanno et al. (2004). All three compounds reduced the proliferation of preosteoblasts but only BPA $(1 \mu \mathrm{M}$ to $10 \mu \mathrm{M})$ alone increased the activity of alkaline phosphatase and cellular calcium content [27]. This might indicate that BPA promoted early osteoblast differentiation in this study. The results of Kanno et al. (2004) were significantly different from Hwang et al. (2013), possibly due to use of stripped foetal blood serum (FBS) and the range of concentrations used. Stripped FBS avoids the interference of endogenous stimulants for growth but it is not similar with the in vivo condition. Mika et al. (2016) showed that BPA might exert its effects on osteoblasts through steroid and xenobiotic receptor (SXR). This receptor was only detected in osteoblasts but not osteoclasts of adult and foetal bone tissues. Treatment with BPA increased SXR responsive genes in human foetal preosteoblast cell line (hFOB transfected with SXR) and osteoblast-like cells, MG-63. The proliferation and collagen productions of hFOB transfected with SXR were increased at lower concentrations of BPA compared to control cells [28].

The effects of long-term exposure to BPA and its analogues, bisphenol AF (BPAF) and bisphenol S (BPS) $(10 \mathrm{nM})$ on human osteosarcoma cells were compared [29]. After three months of exposure, BPAF and BPS significantly enriched 5 and 11 skeletal biological processes according to the genome-wide gene expression assay, but BPA exposure was not associated with changes in any skeletal genes [29]. Some of the processes enhanced by BPAF and BPS included development of embryonic skeletal system, osteoclast differentiation and hedgehog signalling 
pathway [29]. Bisphenol AF by itself enriched TGF-beta signalling pathway whereas BPS reduced expression of genes related to Wnt signalling pathway (low-density lipoprotein receptor-related protein 5 and Wnt5A) and specific osteoblast markers (RUNX-2, osteoprotegerin, collagen type 1 alpha 1) [29]. The differential effects of BPA analogues on skeletal process might be related to their affinity towards cell receptors. For instance, BPAF was shown to have a higher affinity towards oestrogen receptor and thus higher oestrogenic activities [30]. A derivative of BPA, bisphenol A diglycidyl ether (BADGE), is a potent antagonist of peroxisome proliferator-activated receptor gamma (PPAR $\gamma$ ). Yu et al. (2012) showed that human bone mesenchymal stem cells incubated with BADGE demonstrated lower adipogenesis but not higher osteogenesis [31].

Osteoclasts reabsorb damaged bone and make way for new bone formation. However, excessive reabsorption can damage bone health. In cellular studies, osteoclasts are differentiated from macrophages using specific factors [32]. Formation of tartrate resistance acid phosphatase (TRAP) positive cells (osteoclast-like cells) from RAW 264.7 macrophages were dose-dependently reduced by
BPA (0.5-12.5 $\mu \mathrm{M})$ [26]. This was associated with suppressed expression of osteoclastic genes, receptor activator of nuclear factor-kB (RANK) and nuclear factor of activated $\mathrm{T}$ cells (NFATc1) triggered by inhibition of JNK, p38, ERK and Akt phosphorylation [26]. The viability of RAW 264.7 macrophages was also decreased by BPA. This was induced by decreasing the expression of BCL2 and upregulation of caspases 3 and 8 (initiator of apoptosis) [26]. Overall, in vitro studies of BPA on osteoclasts are limited.

The effects of BPA and its derivatives on bone cells are summarized in Figure 1.

\section{Evidence from animal studies}

Many studies have been conducted on the effects of BPA on skeletal health in rodents, ranging from the foetal/neonate skeletal development model, the diabetic bone loss to the classic oestrogen deficiency (knockout or castrated) osteoporosis model. This appropriately encompasses the skeletal health from early development to old age similar in humans.

Developmental programming or changes in metabolic environmental during the prenatal and postnatal period can influence disease development in the later stage of life [33]. To investigate the effects
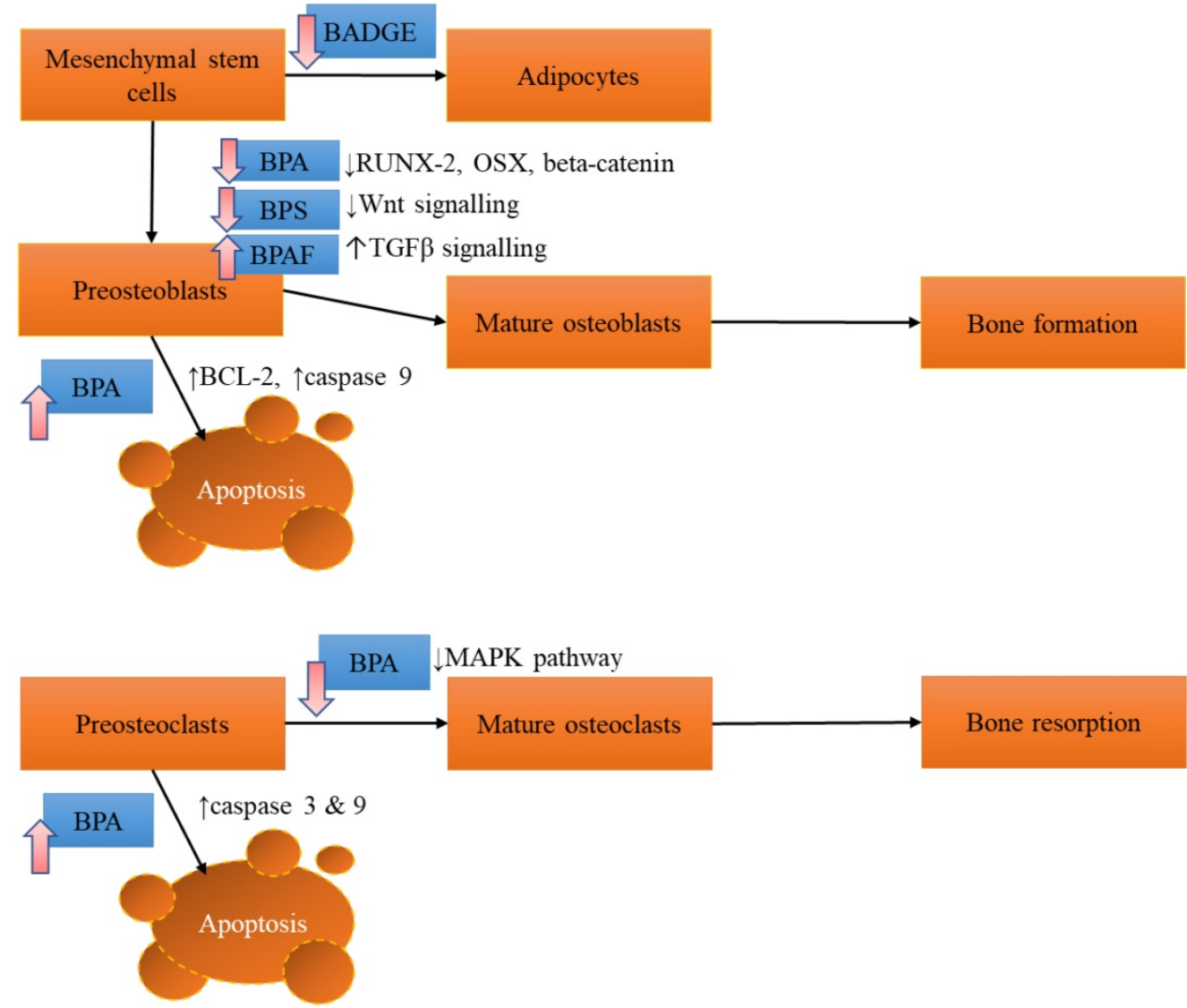

Figure 1. The effects of BPA and its derivatives on bone cells. The effect varies according to the derivatives, probably depending on the affinity towards different receptors on bone cells. Abbreviations: $B A D G E=b i s p h e n o l ~ A$ diglycidyl ether; BPAF=bisphenol AF; $B P A=b i s p h e n o l ~ A ; B P S=b i s p h e n o l ~ S ; M A P K=$ mitogen-activated protein kinase; RUNX-2=runt related factor-2; OSX=osterix; TGF $\beta=$ transforming growth factor beta. 
of xenoestrogens on skeletal programming, Pelch et al. (2012) compared the skeletal effects of BPA, diethylstilbestrol (DES, used in hormone replacement), and ethinyl oestradiol (EE, used in oral contraceptives) exposure to mice nine days prenatal and 12 days postnatal [34]. The skeletal health of these mice was assessed during adulthood when they had reached peak bone mass. The study revealed that exposure to $10 \mu \mathrm{g} / \mathrm{kg} /$ day BPA significantly increased femoral length in male mice but decrease biomechanical strength (energy to failure) in female mice [34]. In contrast, DES and EE increased the femur length in female mice but decreased biomechanical strength in mice [34]. In addition, male mice exposed to $0.1 \mu \mathrm{g} / \mathrm{kg} /$ day DES had significantly lower marrow cavity diameter, higher cortical bone width, lower endosteal to periosteal medio-lateral diameter ratio [34]. This was not seen in other treatment groups. None of the treatment affected circulating bone remodelling markers [34]. The stronger effects of DES on bone compared to BPA might arise due to a stronger oestrogen receptor binding affinity. This study showed that early exposure of BPA, EE or DES could lead to reduced bone strength and low-trauma fractures.

In a similar study, Lejonklou et al. supplemented Wistar rats with $25-50,000 \mu \mathrm{g} / \mathrm{kg}$ BPA from gestational day 7 until 22 days postnatal. Their bone health was examined at three months old. The results showed that femoral length of the rats exposed to all doses of BPA was significantly higher than controls [20]. The femoral diaphyseal bone mineral content (BMC) of the female rats exposed to BPA at $250 \mu \mathrm{g} / \mathrm{kg}$ was significantly lower compared to rats exposed to $50,000 \mu \mathrm{g} / \mathrm{kg}$ BPA [20]. Male rats exposed to $25 \mu \mathrm{g} / \mathrm{kg}$ BPA had significant thicker diaphyseal cortex, total and cortical BMC, as well as cortical cross-sectional area compared to rats exposed to $250 \mu \mathrm{g} / \mathrm{kg}$ BPA [20]. Bone biomechanical strength and metaphyseal geometry of the femur was not affected by BPA exposure [20]. This did not necessarily indicate the skeletal geometrical changes were insufficient to produce a specific effect. Since the biomechanical test (three-point-bending) only applied stress to a certain part of the bone, it might not reflect the weakest bone segment. This study highlighted the gender difference in the skeletal response of the rats towards moderate exposure of BPA in their early stage of life. Bone mineral content deteriorated in female rats but increased in the male rats. The exact reason is not known at the moment.

Female aromatase-knockout (ArKO) mice are a model of oestrogen deficiency because they lack aromatase enzymes essential in the production of oestrogen [35]. Toda et al. (2002) supplemented five-week-old female ArKO mice with $0.1 \%$ or $1.0 \%$ $(\mathrm{w} / \mathrm{w}) \mathrm{BPA}$ in the diet for five months. They found that BPA exhibited strong oestrogenic effects by preventing the degeneration of uteri and ovaries, normalizing the gene expression of progesterone receptor and vascular endothelial growth factor in the uteri and insulin-like growth factor-1 receptor, bone morphogenetic protein-15 and growth differentiation factor-9 in the ovaries of ArKO mice [36]. With regards to their bone health, total BMD of the ArKO mice was improved in a dose-dependent manner by BPA. Peripheral quantitative computed tomography demonstrated that degenerative changes in the femoral trabecular bone of the ArKO mice were reversed by BPA [36]. In contrast, BPA did not improve $\mathrm{BMD}$ and bone structure of the wildtype mice in this study [36]. This might be due to the relatively lower binding affinity of BPA to oestrogen receptors compared with oestrogens $(2,000-10,000$ fold lower compared to 17 $\beta$-oestradiol) [37]. It should be noted that the dose of BPA used in this study (1\% in diet) was $1 \times 10^{5}$ higher than the environmental exposure.

Seidlova-Wuttke et al. (2004) compared the oestrogenic effects of BPA (37 or $370 \mathrm{ug} / \mathrm{kg}$ ), dibutylphtalate (DBP, 92.5 or $462.5 \mathrm{mg} / \mathrm{kg}$ ) and benzophenone-2 (BP2, 185 or $925 \mathrm{mg} / \mathrm{kg}$ ) in ovariectomized rats for three months. The affinity of BPA to ER- $\beta$ was high but to ER-a was low in oestrogen-binding assay [38]. However, oestrogenic activities of BPA on oestrogenic responsive tissues, such as uterine epithelium, endometrium and myometrium were not significant [38]. With respect to skeletal health, BPA reduced the trabecular density at the tibial metaphyseal of the ovariectomized rats by $5 \%$. Osteocalcin (bone formation marker) level was increased in BPA-treated rats but C-terminal of collagen crosslinks (bone resorption marker) level was not affected [38]. In contrast, BP2 exhibits strong oestrogenic activities on uterine tissues and increased tibial metaphyseal trabecular bone density, while DBP had the least effects on uterine and bone tissues [38]. The researchers suggested that the oestrogenic activities of BPA were overcome by its antiandrogenic and aryl hydrocarbon receptor binding activities, which were associated with reduced bone health.

A derivative of BPA, BADGE, is a component of epoxy resin coatings for cans, tanks and concrete vats [39]. The skeletal effects of BADGE on bone have also been studied. Botolin and McCabe (2006) administered BADGE at $30 \mathrm{mg} / \mathrm{kg}$ daily (i.p.) to 15-week-old male mice with insulin-deficient induced by streptozotocin and normal mice. These mice suffered from bone loss, bone marrow adiposity, hyperglycaemia and hyperlipidaemia induced by 
diabetes [40]. Treatment with BADGE inhibited the development of hyperlipidaemia and bone marrow adiposity but not bone loss and suppression of bone formation genes (runt-related factor 2 and osteocalcin) [40]. By itself, BADGE did not suppress osteoblastrelated gene expression or decrease the bone mineral density of the rats [40].

In a subsequent study by Duque et al. (2012), nine-month-old male mice were treated with BADGE alone (30 mg/kg i.p. daily) or in combination with 1,25-dihydroxyvitamin $\mathrm{D}$ (the biologically active form of vitamin $\mathrm{D}$, delivered using a subcutaneous osmotic pump, $18 \mathrm{mp} /$ day) for six weeks. Mice receiving BADGE alone or in combination with 1,25dihydroxyvitamin D showed increased bone volume, trabecular number, thickness and unmineralized osteoid at the distal femoral metaphysis [41]. This might be contributed by increased bone formation, indicated by higher levels of osteocalcin (bone formation marker), osteoblast number and mineral apposition rate (at both cortical and trabecular bone) at the femur of the stated groups [41]. The treatment also reduced bone marrow adiposity concurrently with the downregulation of genes related to adipogenesis (PPARY and CCAAT/enhancer binding protein a $(\mathrm{C} / \mathrm{EBPa}))$ [41]. The extracted bone marrow cells from mice treated with BADGE and 1,25-dihydroxyvitamin $\mathrm{D}$ showed more colony forming units and higher protein expression of osteocalcin and runt-related factor-2, but a lower expression of osteopontin [41]. Osteopontin expression is critical in bone mineralization. Therefore, the researchers suggested that the lower osteopontin expression was related to the unmineralized osteoid, demonstrating high bone matrix synthesis exceeding its capability to mineralized.
$\mathrm{Li}$ et al. investigated the effects of BADGE (30 $\mathrm{mg} / \mathrm{kg}$ daily for 12 weeks, i.p.) on five-month-old ovariectomized or normal female rats. Bone structural indices were improved in normal female rats receiving BADGE, demonstrated by increased bone density and volume, increased trabecular thickness, number and lower separation. This was contributed by increased bone formation, indicated by higher mineral apposition rate, bone formation rate, osteoblast number and N-terminal propeptide of type I collagen (a bone formation marker) [21]. Bone marrow adiposity was lowered in the treated group [21]. These physical changes were reflected in the gene expression level, whereby the expression of adipogenesis gene (PPARY and C/EBPa) was lowered while expression of osteogenesis genes (osteocalcin and RUNX2) was increased with treatment [21]. The beneficial skeletal effects of BADGE were attenuated by ovariectomy. Apart from a reduced trabecular separation and bone marrow adiposity, no other changes including gene expression were detected in BADGE treated ovariectomized rats [21].

Figure 2 shows the effects of BPA and its derivatives on rodents in various models, ranging from prenatal exposure to disease states.

\section{Evidence from human studies}

Two cross-sectional studies have examined the relationship between BPA and bone health in humans. A small-scale study among 51 Korean post-menopausal women aged between 50-82 years (mean age 64.5 years) receiving osteoporotic treatment in a hospital found that serum BPA did not correlate significantly with bone mineral density (lumbar spine, total femur and femoral neck), body mass index, 25-hydroxyvitamin $\mathrm{D}$ and bone remodelling markers [42]. Since the sample size was small, this study might be underpowered. The subjects were restricted to women on osteoporosis treatment, which might mask the effects of BPA on bone [42]. In a population of 246 pre- and post-menopausal Chinese women from Shanghai China aged 35.2 \pm 0.6 years, positive relationships between urinary BPA level, fat mass and leptin level were found [43]. However, the associations between urinary BPA and bone mineral density (lumbar spine and femoral neck), bone remodelling markers, serum oestradiol level were not significant after the adjustment with
Figure 2. The skeletal effects of BPA and BADGE in animal models. Abbreviation: ArKO=aromatase knock-out; $B M C=$ bone mineral content; $B M D=$ bone mineral density;

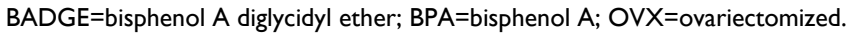


body mass index [43]. In the final multivariate model, fat-free mass was a strong predictor of bone mineral density in these subjects instead of fat mass [43]. This might explain the absence of mediating effects by BPA in the relationship between body anthropometry and bone mineral density [43]. It should be noted that these women were healthy, with regular menses and normal body mass index $\left(21.2 \pm 0.2 \mathrm{~kg} / \mathrm{m}^{2}\right)$, so they were not at risk for osteoporosis [43]. To date, no study has been performed to investigate the relationship between BPA level and risk of fragility fracture.

\section{Discussion}

The pharmacokinetics studies on BPA revealed that it undergoes rapid and extensive metabolism in the body [44]. Most of the BPA undergoes glucuronidation and sulfation by the liver to form hydrophilic products and a very small amount is excreted unchanged via the biliary route or urine [45]. More than $90 \%$ of the BPA is eliminated 24 hours after ingestion [44]. Typical BPA exposure through food ingestion would produce picomolar or subpicomolar circulating concentration in the body [46]. Deposition of BPA in body tissues is not well characterised but some studies showed that it can be found in the adipose tissue and breast milk of humans $[47,48]$. The BPA level in skeletal tissue is relatively unknown. Therefore, it is difficult to judge whether the concentrations in cellular studies or dosage in animal studies are realistic.

There is evidence reporting that the dose-response of BPA is biphasic non-monotonic [49, 50]. One study summarised that $20 \%$ of the published dose-response studies on BPA demonstrated this characteristic [50]. This suggests that the dose-response curve of BPA could be inverted-U shaped. It might be beneficial at lower doses, and harmful to the bone at higher doses. This would explain some of the heterogeneous results seen in bone cell studies. However, this property of BPA on bone is not scrutinized more closely in any study and remains speculative at best at this moment.

Studies on the relationship between BPA level and bone health are scarce at this moment. The two available studies that examined the association between BPA level and bone mineral density demonstrated a non-significant relationship [42, 43]. Besides, the populations studied are small. The subjects in the study by Zhao et al. (2012) were relatively young and they were not at risk of developing osteoporosis [43]. Meanwhile, Kim et al. (2012) studied an osteoporotic population receiving osteoporosis treatment [42]. Thus, the relationship between BPA and bone health in humans is not conclusive and awaits larger studies. Longitudinal cohort studies are necessary to investigate the risk of fragility fracture and BPA exposure.

Ultimately, it is hard to quantify the effects of a single xenoestrogen on bone health in humans as we are constantly exposed to a myriad of pollutants with potential skeletal effects. Phthalates, 1,1 -dichloro-2,2-bis(p-chloropheny1)-ethylene (DDE), dioxin and cadmium are some of the pollutants exhibiting skeletal activities in humans [51-54]. This was confounded by the presence of dietary and endogenous factors that regulate bone metabolism [55-59]. Hence, it is impossible to delineate the skeletal action of each pollutant in humans.

\section{Conclusion}

Bisphenol $\mathrm{A}$ is an endocrine disruptor which could affect bone. However, due to the cellular and animal model used in the investigations, the skeletal effects of BPA and its derivatives are heterogeneous (Table 1), whereby both positive and negative effects have been reported. A possible gender effect of BPA on bone has been revealed in animal studies (beneficial in males, deleterious in females) but this awaits further examinations. There is a paucity of epidemiological studies on the effects of BPA exposure and bone health in humans. The current evidence from cross-sectional studies revealed a negligible relationship between BPA level and bone mineral density but this is not conclusive. A more comprehensive longitudinal study is needed to verify the relationship BPA and bone health in humans, especially in fracture risk assessment.

Table 1. The skeletal effects of bisphenol $A$ and its derivatives

\begin{tabular}{|c|c|c|}
\hline Compounds & In vitro actions & In vivo actions \\
\hline Bisphenol A & $\begin{array}{l}\text { Inhibit osteoblast } \\
\text { formation. } \\
\text { Induce apoptosis of } \\
\text { osteoblasts and } \\
\text { osteoclasts. }\end{array}$ & $\begin{array}{l}\text { Decrease bone strength and bone } \\
\text { mineral content in female rodents } \\
\text { but increase bone strength and } \\
\text { bone mineral content in male } \\
\text { rodents prenatally. } \\
\text { Further induce bone loss in } \\
\text { ovariectomized rats. }\end{array}$ \\
\hline Bisphenol AF & $\begin{array}{l}\text { Encourage osteoblast } \\
\text { formation. }\end{array}$ & Not tested. \\
\hline Bisphenol S & $\begin{array}{l}\text { Inhibit osteoblast } \\
\text { formation. }\end{array}$ & Not tested. \\
\hline $\begin{array}{l}\text { Bisphenol A } \\
\text { diglycidyl ether }\end{array}$ & $\begin{array}{l}\text { Inhibit adipocyte } \\
\text { formation. }\end{array}$ & $\begin{array}{l}\text { Promote bone formation in normal } \\
\text { rats. } \\
\text { Decrease bone loss in } \\
\text { ovariectomized rats. }\end{array}$ \\
\hline
\end{tabular}

\section{Acknowledgement}

We thank Universiti Kebangsaan Malaysia for funding the researchers through GUP-2017-060 and AP-2017-009/1. 


\section{Competing Interests}

The authors have declared that no competing interest exists.

\section{References}

1. Staples Ca, Dom PB, Klecka GM, Sandra TO, Harris LR. A review of the environmental fate, effects, and exposures of Bisphenol A. Chemosphere. 1998; 36: 2149-73.

2. Huang $Y Q$, Wong $C K$, Zheng JS, Bouwman $H$, Barra R, Wahlstrom B, et al. Bisphenol A (BPA) in China: a review of sources, environmental levels, and potential human health impacts. Environ Int. 2012; 42: 91-9.

3. Morgan $\mathrm{MK}$, Nash $\mathrm{M}$, Barr DB, Starr JM, Scott Clifton M, Sobus JR. Distribution, variability, and predictors of urinary bisphenol A levels in 50 North Carolina adults over a six-week monitoring period. Environment International. 2018; 112: 85-99.

4. Toner F, Allan G, Dimond SS, Waechter JM, Beyer D. In vitro percutaneous absorption and metabolism of Bisphenol A (BPA) through fresh human skin. Toxicology in Vitro. 2018; 47: 147-55.

5. Björnsdotter MK, de Boer J, Ballesteros-Gómez A. Bisphenol A and replacements in thermal paper: A review. Chemosphere. 2017; 182: 691-706.

6. Jalal N, Surendranath AR, Pathak JL, Yu S, Chung CY. Bisphenol A (BPA) the mighty and the mutagenic. Toxicology Reports. 2018; 5: 76-84

7. Bolli A, Galluzzo P, Ascenzi P, Del Pozzo G, Manco I, Vietri MT, et al. Laccase treatment impairs bisphenol A-induced cancer cell proliferation affecting estrogen receptor alpha-dependent rapid signals. IUBMB Life. 2008; 60: 843-52.

8. Bolli A, Bulzomi P, Galluzzo P, Acconcia F, Marino M. Bisphenol A impairs estradiol-induced protective effects against DLD-1 colon cancer cell growth. IUBMB Life. 2010; 62: 684-7.

9. Akingbemi BT, Sottas CM, Koulova AI, Klinefelter GR, Hardy MP. Inhibition of testicular steroidogenesis by the xenoestrogen bisphenol $\mathrm{A}$ is associated with reduced pituitary luteinizing hormone secretion and decreased steroidogenic enzyme gene expression in rat Leydig cells. Endocrinology. 2004; 145: 592-603.

10. Castro B, Sanchez P, Torres JM, Preda O, del Moral RG, Ortega E. Bisphenol A Exposure during Adulthood Alters Expression of Aromatase and 5a-Reductase Isozymes in Rat Prostate. PLoS One. 2013; 8: e55905.

11. Kim JY, Han EH, Kim HG, Oh KN, Kim SK, Lee KY, et al. Bisphenol A-induced aromatase activation is mediated by cyclooxygenase-2 up-regulation in rat testicular Leydig cells. Toxicol Lett. 2010; 193: 200-8.

12. Liu Y, Mei C, Liu H, Wang H, Zeng G, Lin J, et al. Modulation of cytokine expression in human macrophages by endocrine-disrupting chemical Bisphenol-A. Biochem Biophys Res Commun. 2014; 451: 592-8.

13. Ooe $\mathrm{H}$, Taira $\mathrm{T}$, Iguchi-Ariga $\mathrm{SM}$, Ariga $\mathrm{H}$. Induction of reactive oxygen species by bisphenol A and abrogation of bisphenol A-induced cell injury by DJ-1. Toxicol Sci. 2005; 88: 114-26.

14. Lin Y, Sun X, Qiu L, Wei J, Huang O, Fang C, et al. Exposure to bisphenol A induces dysfunction of insulin secretion and apoptosis through the damage of mitochondria in rat insulinoma (INS-1) cells. Cell Death Dis. 2013; 4: e460.

15. Xin F, Jiang L, Liu X, Geng C, Wang W, Zhong L, et al. Bisphenol A induces oxidative stress-associated DNA damage in INS-1 cells. Mutat Res Genet Toxicol Environ Mutagen. 2014; 769: 29-33.

16. Yang YJ, Hong YC, Oh SY, Park MS, Kim H, Leem JH, et al. Bisphenol A exposure is associated with oxidative stress and inflammation in postmenopausal women. Environ Res. 2009; 109: 797-801.

17. Savastano S, Tarantino G, D'Esposito V, Passaretti F, Cabaro S, Liotti A, et al. Bisphenol-A plasma levels are related to inflammatory markers, visceral obesity and insulin-resistance: a cross-sectional study on adult male population. J Transl Med. 2015; 13: 169.

18. Wauquier F, Leotoing L, Coxam V, Guicheux J, Wittrant Y. Oxidative stress in bone remodelling and disease. Trends in Molecular Medicine. 2009; 15: 468-77.

19. Mundy GR. Osteoporosis and Inflammation. Nutrition Reviews. 2007; 65: S147-S51.

20. Lejonklou MH, Christiansen S, Orberg J, Shen L, Larsson S, Boberg J, et al. Low-dose developmental exposure to bisphenol A alters the femoral bone geometry in wistar rats. Chemosphere. 2016; 164: 339-46.

21. Li G, Xu Z, Hou L, Li X, Li X, Yuan W, et al. Differential effects of bisphenol A diglicydyl ether on bone quality and marrow adiposity in ovary-intact and ovariectomized rats. Am J Physiol Endocrinol Metab. 2016; 311: E922-e7.

22. Florencio-Silva R, Sasso GR, Sasso-Cerri E, Simoes MJ, Cerri PS. Biology of Bone Tissue: Structure, Function, and Factors That Influence Bone Cells. Biomed Res Int. 2015; 2015: 421746

23. McGowan JA. Bone: target and source of environmental pollutant exposure. Otolaryngol Head Neck Surg. 1996; 114: 220-3.

24. Xiao W, Wang Y, Pacios S, Li S, Graves DT. Cellular and Molecular Aspects of Bone Remodeling. Front Oral Biol. 2016; 18: 9-16.

25. Mechiche Alami S, Gangloff SC, Laurent-Maquin D, Wang Y, Kerdjoudj H. Concise Review: In Vitro Formation of Bone-Like Nodules Sheds Light on the Application of Stem Cells for Bone Regeneration. Stem Cells Transl Med. 2016; 5: $1587-93$
26. Hwang JK, Min KH, Choi KH, Hwang YC, Jeong IK, Ahn KJ, et al. Bisphenol A reduces differentiation and stimulates apoptosis of osteoclasts and osteoblasts. Life Sci. 2013; 93: 367-72.

27. Kanno S, Hirano S, Kayama F. Effects of phytoestrogens and environmental estrogens on osteoblastic differentiation in MC3T3-E1 cells. Toxicology. 2004; 196: 137-45.

28. Miki Y, Hata S, Nagasaki S, Suzuki T, Ito K, Kumamoto H, et al. Steroid and xenobiotic receptor-mediated effects of bisphenol A on human osteoblasts. Life Sci. 2016; 155: 29-35.

29. Fic A, Mlakar SJ, Juvan P, Mlakar V, Marc J, Dolenc MS, et al. Genome-wide gene expression profiling of low-dose, long-term exposure of human osteosarcoma cells to bisphenol A and its analogs bisphenols AF and S. Toxicol In Vitro. 2015; 29: 1060-9.

30. Cao LY, Ren XM, Li CH, Zhang J, Oin WP, Yang Y, et al. Bisphenol AF and Bisphenol B Exert Higher Estrogenic Effects than Bisphenol A via G Protein-Coupled Estrogen Receptor Pathway. Environ Sci Technol. 2017; 51: 11423-30.

31. Yu WH, Li FG, Chen XY, Li JT, Wu YH, Huang LH, et al. PPARgamma suppression inhibits adipogenesis but does not promote osteogenesis of human mesenchymal stem cells. Int J Biochem Cell Biol. 2012; 44: 377-84.

32. Takahashi N, Udagawa N, Kobayashi Y, Suda T. Generation of osteoclasts in vitro, and assay of osteoclast activity. Methods Mol Med. 2007; 135: 285-301.

33. Nesterenko TH, Aly H. Fetal and neonatal programming: evidence and clinical implications. Am J Perinatol. 2009; 26: 191-8.

34. Pelch KE, Carleton SM, Phillips CL, Nagel SC. Developmental exposure to xenoestrogens at low doses alters femur length and tensile strength in adult mice. Biology of Reproduction. 2012; 86.

35. Fisher $\mathrm{CR}$, Graves $\mathrm{KH}$, Parlow AF, Simpson ER. Characterization of mice deficient in aromatase (ArKO) because of targeted disruption of the cyp19 gene. Proc Natl Acad Sci U S A. 1998; 95: 6965-70.

36. Toda K, Miyaura C, Okada T, Shizuta Y. Dietary bisphenol A prevents ovarian degeneration and bone loss in female mice lacking the aromatase gene (Cyp19 ). Eur J Biochem. 2002; 269: 2214-22.

37. Acconcia F, Pallottini V, Marino M. Molecular Mechanisms of Action of BPA. Dose-Response. 2015; 13: 1559325815610582.

38. Seidlova-Wuttke D, Jarry H, Wuttke W. Pure estrogenic effect of benzophenone-2 (BP2) but not of bisphenol A (BPA) and dibutylphtalate (DBP) in uterus, vagina and bone. Toxicology. 2004; 205: 103-12.

39. [Internet] National Center for Biotechnology Information. Bisphenol A diglycidyl ether https://pubchem.ncbi.nlm.nih.gov/compound/2286 Last Update: 13/1/2018. Accessed: 16/1/2018

40. Botolin S, McCabe LR. Inhibition of PPARgamma prevents type I diabetic bone marrow adiposity but not bone loss. J Cell Physiol. 2006; 209: 967-76.

41. Duque G, Li W, Vidal C, Bermeo S, Rivas D, Henderson J. Pharmacological inhibition of PPARgamma increases osteoblastogenesis and bone mass in male C57BL/ 6 mice. J Bone Miner Res. 2013; 28: 639-48.

42. Kim DH, Oh CH, Hwang YC, Jeong IK, Ahn KJ, Chung HY, et al. Serum bisphenol a concentration in postmenopausal women with osteoporosis. J Bone Metab. 2012; 19: 87-93.

43. Zhao HY, Bi YF, Ma LY, Zhao L, Wang TG, Zhang LZ, et al. The effects of bisphenol A (BPA) exposure on fat mass and serum leptin concentrations have no impact on bone mineral densities in non-obese premenopausal women. Clin Biochem. 2012; 45: 1602-6.

44. Thayer KA, Doerge DR, Hunt D, Schurman SH, Twaddle NC, Churchwell MI, et al. Pharmacokinetics of bisphenol A in humans following a single oral administration. Environ Int. 2015; 83: 107-15.

45. Kurebayashi H, Betsui H, Ohno Y. Disposition of a low dose of 14C-bisphenol A in male rats and its main biliary excretion as BPA glucuronide. Toxicol Sci. 2003: 73 : $17-25$.

46. Teeguarden JG, Twaddle NC, Churchwell MI, Yang X, Fisher JW, Seryak LM, et al. 24-hour human urine and serum profiles of bisphenol A: Evidence against sublingual absorption following ingestion in soup. Toxicol Appl Pharmacol. 2015; 288: 131-42.

47. Fernandez MF, Arrebola JP, Taoufiki J, Navalon A, Ballesteros O, Pulgar R, et al. Bisphenol-A and chlorinated derivatives in adipose tissue of women. Reprod Toxicol. 2007; 24: 259-64.

48. Kuruto-Niwa R, Tateoka Y, Usuki Y, Nozawa R. Measurement of bisphenol A concentrations in human colostrum. Chemosphere. 2007; 66: 1160-4.

49. vom Saal FS, Hughes C. An Extensive New Literature Concerning Low-Dose Effects of Bisphenol A Shows the Need for a New Risk Assessment. Environmental Health Perspectives. 2005; 113: 926-33.

50. Vandenberg LN. Non-monotonic dose responses in studies of endocrine disrupting chemicals: bisphenol a as a case study. Dose Response. 2014; 12: 259-76.

51. DeFlorio-Barker SA, Turyk ME. Associations between bone mineral density and urinary phthalate metabolites among post-menopausal women: a cross-sectional study of NHANES data 2005-2010. Int J Environ Health Res. 2016; 26: 326-45.

52. Eskenazi $B$, Warner $M$, Sirtori $M$, Fuerst $T$, Rauch $S A$, Brambilla $P$, et al Serum dioxin concentrations and bone density and structure in the Seveso Women's Health Study. Environ Health Perspect. 2014; 122: 51-7.

53. Beard J, Marshall S, Jong K, Newton R, Triplett-McBride T, Humphries B, et al. 1,1,1-trichloro-2,2-bis (p-chlorophenyl)-ethane (DDT) and reduced bone mineral density. Arch Environ Health. 2000; 55: 177-80. 
54. James KA, Meliker JR. Environmental cadmium exposure and osteoporosis: a review. Int J Public Health. 2013; 58: 737-45.

55. Chin KY, Ima-Nirwana S. Sex steroids and bone health status in men. Int J Endocrinol. 2012; 2012: 208719.

56. Chin KY, Ima-Nirwana S. The effects of alpha-tocopherol on bone: a double-edged sword? Nutrients. 2014; 6: 1424-41.

57. Chin KY, Ima-Nirwana S. Vitamin $C$ and Bone Health: Evidence from Cell, Animal and Human Studies. Curr Drug Targets. 2018; 19: 439-50.

58. Jolly J, Chin K-Y, Alias E, Chua K, Soelaiman I. Protective Effects of Selected Botanical Agents on Bone. Int J Environ Res Public Health. 2018; 15: 963.

59. Mohamad NV, Soelaiman IN, Chin KY. A concise review of testosterone and bone health. Clin Interv Aging. 2016; 11: 1317-24. 